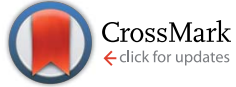

Cite this: RSC Adv., 2017, 7, 14998

Received 10th December 2016 Accepted 23rd February 2017

DOI: $10.1039 / c 6 r a 28009 a$

rsc.li/rsc-advances

\section{Green synthesis of 1-phenyl-1-ortho-xylene ethane in IL and reaction mechanism $\dagger$}

\begin{abstract}
Xuejun Sun, ${ }^{a}$ Xinming Zhou, ${ }^{b}$ Bobo Cao, ${ }^{a}$ Ziping Cao*a and Hui Fu*b
1-Phenyl-1-ortho-xylene ethane (PXE) in IL was synthesized, and the catalysts used were $\mathrm{AlCl}_{3}$ in 1-butyl-3methylimidazolium bromide ([BMIM] [Br]) or 1-butyl-3-methylimidazolium chloride ([BMIM][Cl]), and $\mathrm{H}_{2} \mathrm{SO}_{4}$. When the concentrations of $\mathrm{AlCl}_{3}$ in $\mathrm{IL}$, ortho-xylene and styrene were $0.35,0.03$ and $0.005 \mathrm{~mol}$, respectively, it could be discovered that ([BMIM][Br]) was the best catalyst. When the mole fraction concentration of $\mathrm{AlCl}_{3} /[\mathrm{BMIM}][\mathrm{Br}]$ was more than $0.40 \%$, the reaction was able to achieve $100 \%$ conversion. When the reaction time was longer than 60 minutes, the percentage conversion of orthoxylene attained was $100 \%$. The mechanisms of the reaction were investigated by the DFT method at the B3LYP/6-311++G(d, p) level. The potential energy surface (PES) profile indicated that the energy of transition state was $22.59 \mathrm{kcal} \mathrm{mol}^{-1}$. This indicated that the activation energy of reaction was $28.24 \mathrm{kcal}$ $\mathrm{mol}^{-1}$, which illustrated that the reaction occurred easily. Vibrational frequencies were observed in FT-IR spectra, the corresponding vibrational modes $\nu_{\mathrm{s}}(\mathrm{H} 4-\mathrm{C} 3 \mathrm{Al}-\mathrm{H} 5)$ and $\nu_{\text {as }}(\mathrm{H} 4-\mathrm{C} 3 \mathrm{Al}-\mathrm{H} 5)$ indicated that an $\mathrm{Al}^{3+}$ ion was combined with a C3 atom. In addition, the repeated use of the catalysts was studied; the ionic liquids could still catalyze the reaction and the percentage yield of PXE was larger than $91 \%$ after 6 runs.
\end{abstract}

\section{Introduction}

1-Phenyl-1-ortho-xylene ethane (PXE) and bis(1-phenyl ethanyl) ortho-xylene (BPXE) are synthesis liquids with excellent performance because of their high boiling points, low viscosity, high solubility, low melting points, high-color printer's ability, high dielectric strengths and electrothermal stability, etc., and are widely used in pressure sensitive dye solvents of carbonless paper and electrical insulating oil. In addition, they can also be used as a plasticizer, transformer oil, and other high boiling point solvents. Current commercial alkylation processes are catalyzed primarily by concentrated sulfuric acid or hydrofluoric acid. ${ }^{1}$ The reaction equation is as follows:

The sulfuric acid process produces large amounts of spent acid and acid-soluble oils, which cause serious environmental problems. Anhydrous HF is highly toxic and its leakage produces dangerous stable aerosols at the ground level. In addition, equipment corrosion, transport, hazard management and environmental liability associated with the disposal of

${ }^{a}$ School of Chemistry and Chemical Engineering, Qufu Normal University, Qufu 273165, Shandong, P. R. China. E-mail: caozp_qfiu@163.com; sxjsunxuejun@163. com; qufucaobobo@163.com

${ }^{b}$ State Key Laboratory of Heavy Oil Processing, College of Science, China University of Petroleum, Qingdao 266580, Shandong, P. R. China. E-mail: fuhuiupc@163.com; zhouxinming@upc.edu.cn

$\dagger$ Electronic supplementary information (ESI) available. See DOI: $10.1039 / \mathrm{c} 6 \mathrm{ra} 28009 \mathrm{a}$ spent acids are disadvantages of both processes. To avoid pollution a more environmentally friendly catalyst is desired. ${ }^{2,3}$ unique properties such as a very large liquid temperature range, and they can be made task-specific for certain applications, ${ }^{4}$ which include use as solvents in chemical synthesis and catal$y \operatorname{sis}^{5-11}$ and separation technology, ${ }^{12,13}$ as electrolytes in electrochemical devices, ${ }^{14-16}$ and as lubricants or as heat-transfer fluids. ${ }^{17}$ In addition, there is a huge range of possible combinations of cations and anions, which contribute to the design of ILs. ${ }^{18}$ However, before these liquids can be used commercially on an industrial scale, the process variables need to be optimized in the laboratory, not only in batch and continuous reactor systems for maximum reactant conversion, but also the product yield and catalyst selectivity. Previous studies have demonstrated that the activity of such systems strongly depends on the molar ratio of $\mathrm{AlCl}_{3} / \mathrm{IL}$. Usually, maximal activity can be obtained at a molar ratio of $1.5-2.0$ of $\mathrm{AlCl}_{3}$ to $\mathrm{IL}^{19,20}$

This study reports that 1-phenyl-1-ortho-xylene ethane (PXE) is synthesized in IL and the catalysts used are $\mathrm{AlCl}_{3}$ in 1-butyl-3methylimidazolium bromide ([BMIM][Br]) or 1-butyl-3methylimidazolium chloride ([BMIM][Cl]). The reaction mechanism presented in this work is drawn in the following scheme.

The catalytic activity of a Lewis acid-IL is studied under different experimental conditions, such as different catalysts, concentrations, temperatures and reaction times. The catalysts are facilely isolated from products and effectively recycled. The mechanism of the reaction is determined using quantum
Room temperature ionic liquid (IL) systems have many 


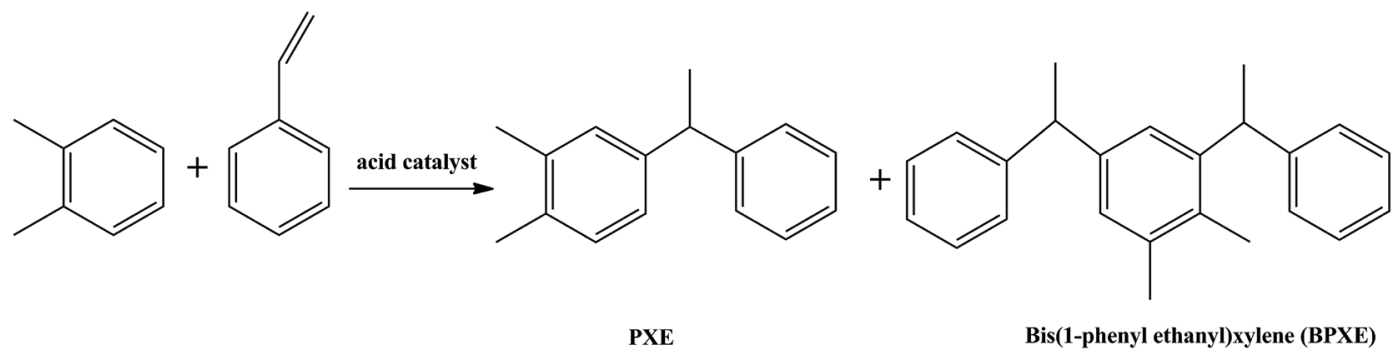

chemical calculations and vibrational frequencies are observed in FT-IR spectra. The repeated use of the catalysts is also investigated.

\section{Experiments}

\subsection{Materials}

High-purity ortho-xylene, styrene and anhydrous $\mathrm{AlCl}_{3}$ were used in this study and purchased from the Tianjin Damao Chemical Reagent Factory (Tianjin, China) and Chinese Medicine Group Chemical Reagent Co, Ltd (Beijing, China). [BMIM] [Cl] (CAS no. 79 917-90-1) and [BMIM][Br] (CAS no. 85 100-77-2) were purchased from the Lanzhou (Lanzhou, China) Center for Green Chemistry with a purity of $99 \%$ and water mass fractions of less than $10^{-3}\left(\mathrm{~g} \mathrm{~g}^{-1}\right)$. To remove traces of volatile compounds, the ILs were kept in a vacuum (about $10^{-6}$ bar) at $343 \mathrm{~K}$ for $24 \mathrm{~h}$ prior to use.

\subsection{Apparatus and measurements}

An Agilent6890 (Agitent Co. USA) gas chromatograph equipped with a flame ionization detector (FID) was employed for analysis. The detector temperature was maintained at $240{ }^{\circ} \mathrm{C}$. The column was programmed with an initial temperature of $60{ }^{\circ} \mathrm{C}$ and this was increased thereafter to $220{ }^{\circ} \mathrm{C}$ at a rate of $15{ }^{\circ} \mathrm{C}$ $\min ^{-1}$. The column used for this purpose was HP-1 with dimensions of $50 \mathrm{~m} \times 0.25 \mathrm{~mm} \times 0.50 \mu \mathrm{m}$.

To support the computational results, Fourier transform infrared (FT-IR) spectra of 2BP8HQ were recorded using a Nicolet iS5 FT-IR spectrometer $\left(4000-525 \mathrm{~cm}^{-1}\right.$; number of scans: 250 ; resolution: $1 \mathrm{~cm}^{-1}$ ) to study the variations of the IR spectra of ortho-xylene and styrene, and the reaction processes.

\subsection{Computational methods}

The reactant (R), intermediate (IM) and transition states (TS) and formed products (P) were fully optimized using the B3LYP/ 6-311++G(d, p) basis set, containing polarizable and diffuse functions, and this well described the weak interactions in the binary systems, especially for intermolecular H-bonded interactions. The interaction energy (DE) was estimated by employing the counterpoise (CP) method for the Gaussian basis set superposition error (BSSE). ${ }^{21}$ From intrinsic reaction coordinate (IRC) calculations and the potential surface (PES) energy profile for the transition state, two desired minima states of the mechanism were obtained. All the DFT calculations were carried out using the Gaussian09 package. ${ }^{22}$

\section{Results and discussion}

\subsection{Solubility of $\mathrm{AlCl}_{3}$ in [BMIM] [Cl] and [BMIM][Br]}

A given amount of anhydrous $\mathrm{AlCl}_{3}$ is slowly added to $3.00 \mathrm{~g}$ of $[\mathrm{BMIM}][\mathrm{Cl}]$ and $[\mathrm{BMIM}][\mathrm{Br}]$ and the mixture is stirred at different temperatures until the catalyst is completely dissolved. $\mathrm{AlCl}_{3} /[\mathrm{BMIM}][\mathrm{Cl}]$ and $\mathrm{AlCl}_{3} /[\mathrm{BMIM}][\mathrm{Br}]$ ionic liquids are thus obtained. The solubility of $\mathrm{AlCl}_{3}$ in [BMIM][Cl] and [BMIM] $[\mathrm{Br}]$ is shown in Table 1. It can be seen that the solubility of $\mathrm{AlCl}_{3}$ increased with the increase of temperature. The solubility of $\mathrm{AlCl}_{3}$ in $[\mathrm{BMIM}][\mathrm{Br}]$ is higher than that in [BMIM][Cl]. The saturation points of $\mathrm{AlCl}_{3}$ in [BMIM][Cl] and [BMIM] $\left.\mathrm{Br}\right]$ are around $50{ }^{\circ} \mathrm{C}$ and $80^{\circ} \mathrm{C}$, respectively. Experimental results also show that the solubility of $\mathrm{AlCl}_{3}$ in [BMIM][Cl] and [BMIM] $[\mathrm{Br}]$ is larger in the latter than in the former. Since the catalytic properties of these binary mixtures depend on their acidities, we can conclude that the catalytic activity of the latter is

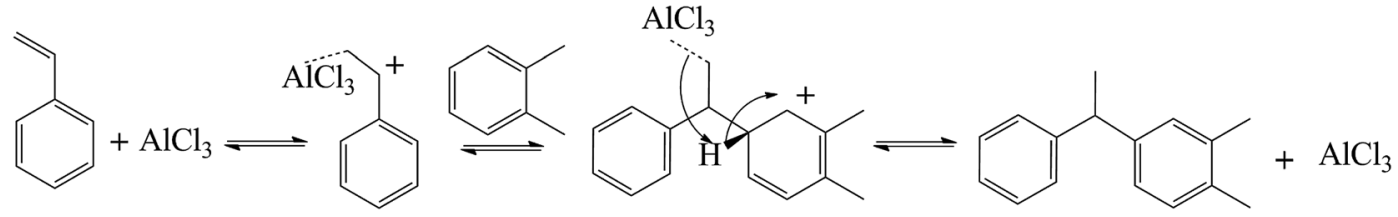


Table 1 Solubility of $\mathrm{AlCl}_{3}$ in $[\mathrm{BMIM]}[\mathrm{Cl}$ and [BMIM][Br]

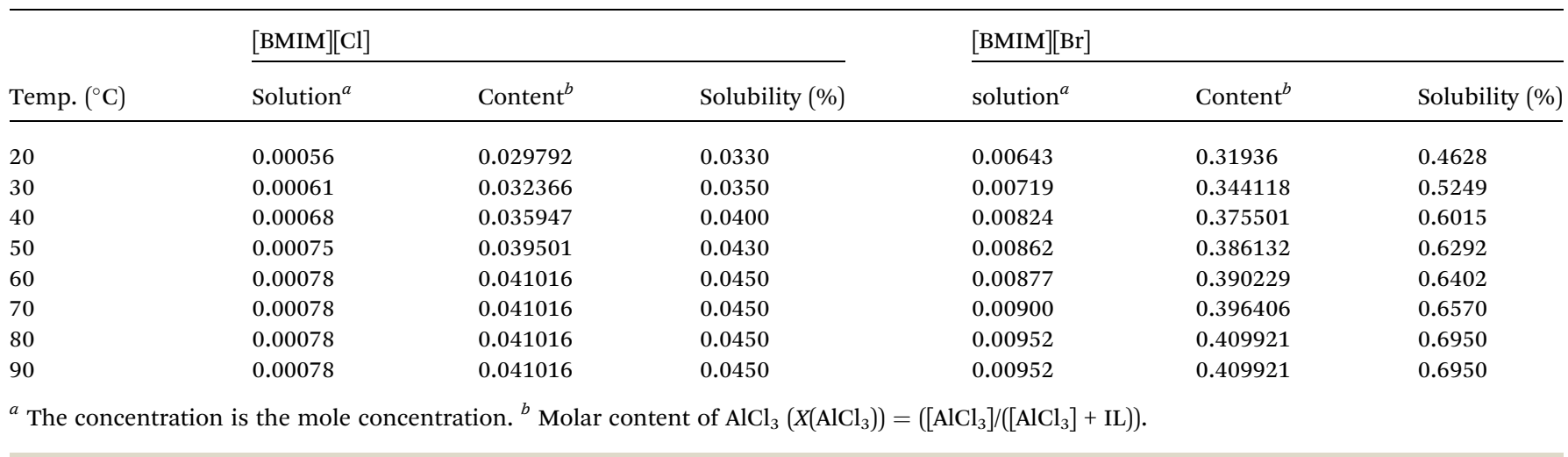

stronger than the former, which can be adjusted by the molar ratio of $\mathrm{AlCl}_{3} / \mathrm{IL}$.

\subsection{Effects of different catalysts on the reaction}

Different catalysts were added to, under the conditions of stirring, solutions of styrene and ortho-xylene dropwise; the reaction is performed in an $80-85^{\circ} \mathrm{C}$ oil bath. TLC (petroleum ether as a solvent) was used to monitor the progress of the reaction. After the completion of the reaction, the reaction liquid was left standing and allowed to cool; the lower layer was separated. The ionic liquid catalyst is rapidly added to small amounts of orthoxylene for the next use. ortho-Xylene is distilled and recovered, and the distillation product is collected at $208-214^{\circ} \mathrm{C}$.

When the concentration of $\mathrm{AlCl}_{3}$ in $\mathrm{IL}$, ortho-xylene and styrene are $0.35,0.03$ and $0.005 \mathrm{~mol}$, respectively, the reactions are performed at $30{ }^{\circ} \mathrm{C}$, the effects of different catalysts on the reaction are shown in Table 2 . It can be seen that the orders of yield are $\mathrm{AlCl}_{3} /[\mathrm{BMIM}][\mathrm{Br}](99 \%)>\mathrm{AlCl}_{3} /[\mathrm{BMIM}][\mathrm{Cl}](73 \%)>$ $\mathrm{H}_{2} \mathrm{SO}_{4}(56 \%)$, which indicated that the yields of $\mathrm{AlCl}_{3}$ in [BMIM] $[\mathrm{Cl}]$ and $[\mathrm{BMIM}][\mathrm{Br}]$ are larger than that of $\mathrm{H}_{2} \mathrm{SO}_{4}$, especially, the yield of $\mathrm{AlCl}_{3} /[\mathrm{BMIM}][\mathrm{Br}]$ reaches $99 \%$. This illustrates that $\mathrm{AlCl}_{3} /[\mathrm{BMIM}][\mathrm{Br}]$ is the best catalyst for the alkylation reaction of ortho-xylene and styrene. Hence, $\mathrm{AlCl}_{3} /[\mathrm{BMIM}][\mathrm{Br}]$ is used as the catalyst in the following experiments.

\subsection{Effects of different mole fractions of $\mathrm{AlCl}_{3} /[\mathrm{BMIM}][\mathrm{Br}]$ on the reaction}

When the amount of ortho-xylene and styrene is 0.03 and $0.005 \mathrm{~mol}$, respectively, the reactions are carried out at $30{ }^{\circ} \mathrm{C}$, and the effect of the different mole fractions of $\mathrm{AlCl}_{3} /[\mathrm{BMIM}]$ $[\mathrm{Br}]$ on the reaction is listed in Table 3 . It can be seen that the percentage conversion of ortho-xylene increased with the increase of the mole fraction of $\mathrm{AlCl}_{3} /[\mathrm{BMIM}][\mathrm{Br}]$, and when the mole fraction of $\mathrm{AlCl}_{3} /[\mathrm{BMIM}][\mathrm{Br}]$ is larger than $0.40 \%$, the percentage conversion of ortho-xylene attained was $100 \%$. This shows that as long as the mole fraction concentration of $\mathrm{AlCl}_{3} /$ [BMIM] $[\mathrm{Br}]$ is more than $0.40 \%$, the reaction will be able to achieve $100 \%$ conversion, and moreover, the rates of formation of PXE and BPXE increased with the increase of the mole fraction of $\mathrm{AlCl}_{3}$ to [BMIM][Br]. The ${ }^{1} \mathrm{H}$ NMR spectrum for a mixture of PXE and BPEX with a $1: 0.36$ ratio is shown in Fig. $\mathrm{S} 1$ (ESI $\dagger$ ). ${ }^{1} \mathrm{H}$ NMR $\left(500 \mathrm{MHz}, \mathrm{CDCl}_{3}\right): \delta$ 7.35-7.20 (m, $\left.3+2.13 \mathrm{H}\right), 7.20-7.10$ $(\mathrm{m}, 4+1.42 \mathrm{H}), 7.08-6.90(\mathrm{~m}, 1+0.71 \mathrm{H}), 4.27(\mathrm{q}, J=7.2 \mathrm{~Hz}, 1 \mathrm{H})$, $4.12(\mathrm{q}, J=7.2 \mathrm{~Hz}, 0.71 \mathrm{H}), 2.29(\mathrm{~s}, 3 \mathrm{H}), 2.21(\mathrm{~s}, 2.13 \mathrm{H}), 2.18(\mathrm{~s}$, $3 \mathrm{H}), 1.63(\mathrm{~d}, J=7.2 \mathrm{~Hz}, 2.13 \mathrm{H}), 1.58$ (d, $J=7.2 \mathrm{~Hz}, 3 \mathrm{H})$. The results are in agreement with the data in ref. 23.

\subsection{Effects of different temperatures on the reaction}

When the amount of ortho-xylene and styrene was 0.03 and $0.005 \mathrm{~mol}$, respectively, the reaction time was 60 minutes and the mole fraction of $\mathrm{AlCl}_{3} /[\mathrm{BMIM}][\mathrm{Br}]$ was $0.40 \%$. The reactions were carried out, and the effects of different temperatures on the reaction are given in Table 4 . It can be seen that the percentage conversion of ortho-xylene increased with the increase of temperature, and when the temperature is higher than $60{ }^{\circ} \mathrm{C}$, the percentage conversion of ortho-xylene attained is $100 \%$. This illustrates that $60{ }^{\circ} \mathrm{C}$ is enough for the reaction. At the same time, the rates of formation of PXE and BPXE

Table 2 Effects of different catalysts on the reaction ${ }^{a}$

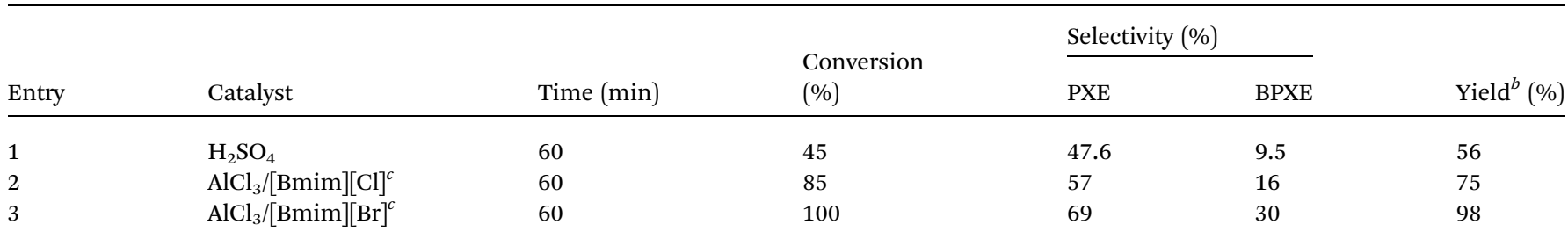

${ }^{a}$ Reaction conditions: ortho-xylene $(0.03 \mathrm{~mol})$, styrene $(0.005 \mathrm{~mol})$ and catalyst $(0.5 \mathrm{~g})$ at $30{ }^{\circ} \mathrm{C} .{ }^{b} \mathrm{GC}$ yield was shown. ${ }^{c} \mathrm{The} \mathrm{mole} \mathrm{ratio} \mathrm{of} \mathrm{AlCl}_{3}$ to $\mathrm{IL}$ is 0.35 . 
Table 3 Effects of different mole fractions of $\mathrm{AlCl}_{3} /[\mathrm{Bmim}] \mathrm{Br}$ on the reaction ${ }^{a}$

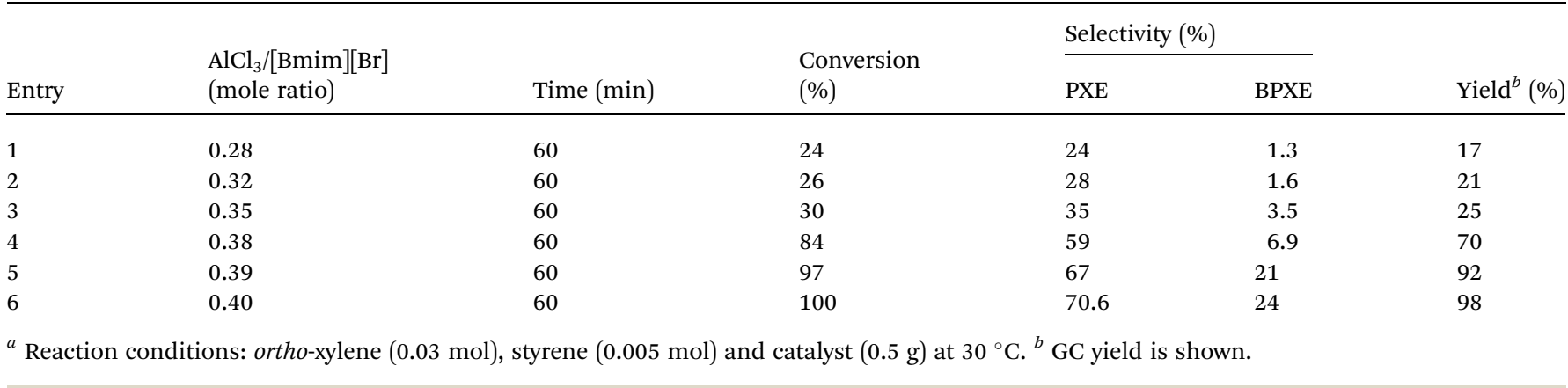

Table 4 Effects of different temperatures on the reaction ${ }^{a}$

\begin{tabular}{|c|c|c|c|c|c|}
\hline \multirow[b]{2}{*}{ Entry } & \multirow{2}{*}{$\begin{array}{l}\text { Temperature } \\
\left({ }^{\circ} \mathrm{C}\right)\end{array}$} & \multirow{2}{*}{$\begin{array}{l}\text { Conversion } \\
(\%)\end{array}$} & \multicolumn{2}{|c|}{ Selectivity (\%) } & \multirow[b]{2}{*}{ Yield $^{b}(\%)$} \\
\hline & & & PXE & BPXE & \\
\hline 1 & 10 & 15 & 14 & 0.6 & 12 \\
\hline 2 & 30 & 97 & 67 & 21 & 92 \\
\hline 3 & 50 & 99 & 69 & 28 & 96 \\
\hline 4 & 70 & 100 & 69 & 30 & 98.3 \\
\hline 5 & 90 & 100 & 69 & 30 & 98.6 \\
\hline 6 & 100 & 100 & 69 & 30 & 99 \\
\hline
\end{tabular}

${ }^{a}$ Reaction conditions: ortho-xylene $(0.03 \mathrm{~mol})$, styrene $(0.005 \mathrm{~mol})$ and $\mathrm{AlCl}_{3} /[\mathrm{Bmim}][\mathrm{Br}](0.5 \mathrm{~g}$, mole ratio: 0.40$)$ at the indicated temperature for 60 minutes. ${ }^{b}$ GC yield is shown.

increased with temperature, which do not vary when the temperature is $60{ }^{\circ} \mathrm{C}$.

\subsection{Effects of different reaction times on the reaction}

When the amount of ortho-xylene and styrene is 0.03 and $0.005 \mathrm{~mol}$, respectively, and the mole fraction of $\mathrm{AlCl}_{3} /[\mathrm{BMIM}]$ $[\mathrm{Br}]$ is $0.40 \%$, the reactions are carried out at $70{ }^{\circ} \mathrm{C}$, and the effects of different reaction times on the reaction are shown in Table 5. It can be seen that the percentage conversion of orthoxylene increased with reaction time, and when the reaction time is longer than 60 minutes, the percentage conversion of orthoxylene attained is $100 \%$. Consequently, according to the above results, the synthesis conditions for obtaining 1-phenyl-1-orthoxylene ethane are that the amounts of ortho-xylene and styrene

Table 5 Effects of different reaction times on the reaction ${ }^{a}$

\begin{tabular}{|c|c|c|c|c|c|}
\hline \multirow[b]{2}{*}{ Entry } & \multirow{2}{*}{$\begin{array}{l}\text { Reaction time } \\
\text { (min) }\end{array}$} & \multirow{2}{*}{$\begin{array}{l}\text { Conversion } \\
(\%)\end{array}$} & \multicolumn{2}{|c|}{$\begin{array}{l}\text { Selectivity } \\
(\%)\end{array}$} & \multirow[b]{2}{*}{ Yield $^{b}(\%)$} \\
\hline & & & PXE & BPXE & \\
\hline 1 & 10 & 18 & 15 & 1.8 & 15 \\
\hline 2 & 30 & 97 & 67 & 21 & 92 \\
\hline 3 & 60 & 100 & 69 & 28 & 97.5 \\
\hline 4 & 90 & 100 & 69 & 30 & 98.6 \\
\hline 5 & 100 & 100 & 69 & 30 & 99 \\
\hline
\end{tabular}

${ }^{a}$ Reaction conditions: ortho-xylene $(0.03 \mathrm{~mol})$, styrene $(0.005 \mathrm{~mol})$ and $\mathrm{AlCl}_{3} /[\mathrm{Bmim}][\mathrm{Br}](0.5 \mathrm{~g}$, mole ratio: 0.40$)$ at $70{ }^{\circ} \mathrm{C} .{ }^{b} \mathrm{GC}$ yield is shown. are 0.03 and $0.005 \mathrm{~mol}$, respectively, the mole fraction of $\mathrm{AlCl}_{3} /$ $[\mathrm{BMIM}][\mathrm{Br}]$ is $0.40 \%$, the reaction time is 60 minutes and the reactions are carried out at $70{ }^{\circ} \mathrm{C}$.

\subsection{Reaction mechanism}

3.6.1 Mechanism of the reaction. Quantum chemical calculations are a useful tool to predict the reaction mechanisms and kinetics of the alkylation reaction. Styrene (R1) and ortho-xylene (R2) have been fully optimized at the B3LYP/6$311++\mathrm{G}(\mathrm{d}, \mathrm{p})$ level, the geometrical parameters involving various species of R1, R2, IM, TS and P are shown in Fig. 1 and $\mathrm{S} 2$ (ESI $\dagger$ ), and the important geometrical parameters are given in Table 6 . It can be seen that styrene has a $\Pi_{8}^{8}$ conjugated structure; for R, the bonds of $\mathrm{C} 1-\mathrm{C} 2$ and $\mathrm{C} 2-\mathrm{C} 3$ are averaged which are 1.390 and $1.486(\AA)$, respectively. When an $\mathrm{Al}^{3+}$ ion is combined with a $\mathrm{C} 3$ atom in styrene, the length of $\mathrm{C} 3-\mathrm{Al}^{3+}$ is $2.101(\AA)$, and the obtained IM joined with ortho-xylene. This illustrates that the $\mathrm{Al}^{3+}$ ion plays an important role in the alkylation processes of styrene and ortho-xylene. From IRC calculations for the transition state (TS), we obtain two desired minima states of the process. This indicates a transition state, and it has an imaginary frequency $\left(-182.63 \mathrm{~cm}^{-1}\right)$, the geometrical parameters of the TS are shown in Fig. 1. In the TS,

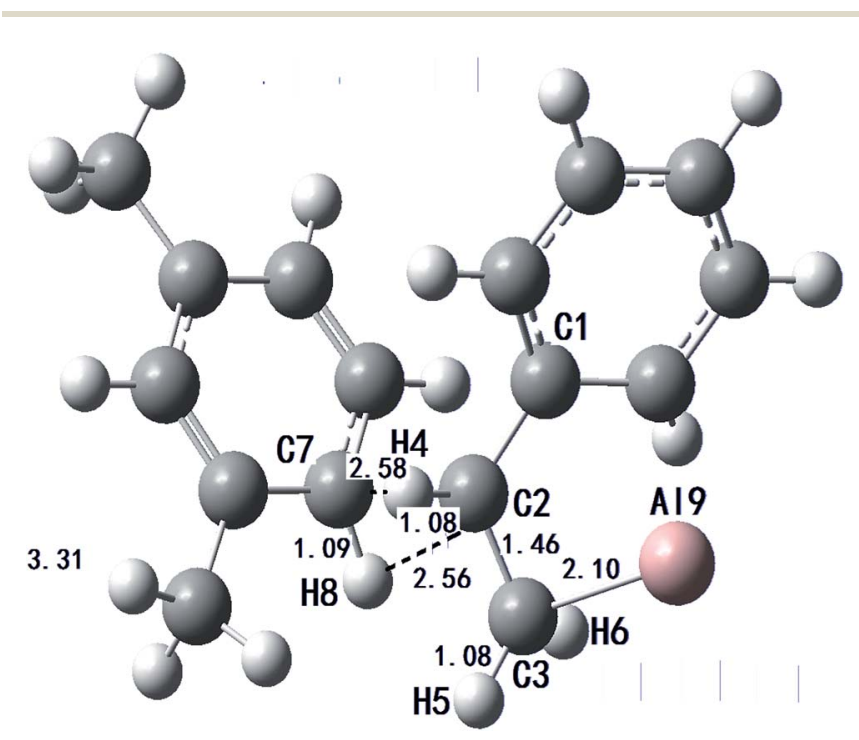

Fig. 1 Geometrical parameters of the TS. 
Table 6 Important geometrical parameters of the R, IM, TS and P $(\AA)$

\begin{tabular}{lllll}
\hline & & & \multicolumn{2}{l}{ Transition } \\
Bond length & Reactant & Intermediate & state & Product \\
\hline C1-C2 & 1.390 & 1.395 & 1.473 & 1.553 \\
C2-C3 & 1.486 & 1.460 & 1.460 & 1.576 \\
C2-H4 & 1.090 & 1.098 & 1.097 & 1.091 \\
C3-H5 & 1.100 & 1.100 & 1.097 & 1.091 \\
C3-H6 & 1.081 & 1.087 & 1.088 & 1.097 \\
C7-H8 & 1.087 & 1.087 & 1.086 & 1.110 \\
C3-Al9 & & 2.101 & 2.101 & 1.965 \\
C2-C7 & & & 2.319 & 1.600 \\
C2-H8 & & & 2.585 & \\
C7-H4 & & & 2.562 & \\
C10-A9 & & & & \\
\end{tabular}

a $\mathrm{C} 2-\mathrm{H} 4-\mathrm{C} 7-\mathrm{H} 8$ four-membered ring is formed, the distances of the bonds are 1.097, 2.562, 1.086 and $2.585(\AA)$, respectively, which provides helpful information on the formation of the $\mathrm{C} 2-$ $\mathrm{C} 7$ bond. The bond lengths of $\mathrm{C} 1-\mathrm{C} 2, \mathrm{C} 2-\mathrm{C} 3$ and $\mathrm{C} 2-\mathrm{C} 7$ are 1.553, 1.576 and $1.600(\AA)$, respectively, which indicates that those bonds are stretched by steric effects of two benzene rings.

The potential energy surface (PES) profile is depicted in Fig. 2. The energy of the IM is lower than that of the reactant by $5.65 \mathrm{kcal} \mathrm{mol}^{-1}$, we can also find that the energy of the $\mathrm{P}$ is higher than that of the IM by $15.69 \mathrm{kcal} \mathrm{mol}^{-1}$. This result indicates that the IM is more stable than the P. The energy of the TS is $22.59 \mathrm{kcal} \mathrm{mol}^{-1}$, and this indicates that the activation energy of the alkylation reaction is $28.24 \mathrm{kcal} \mathrm{mol}^{-1}$. This illustrates that the reaction occurs easily, which is in agreement with the experimental results.

3.6.2 Vibrational frequencies. Table 7 lists the main vibration variations of styrene, styrene + ortho-xylene $+\mathrm{AlCl}_{3}+$ [BMIM][Br] and PXE as well as the IR intensity observed in FT-IR spectra; the corresponding infrared spectra are shown in Fig. S3-S5. $\dagger$ It can be seen that the infrared peak appearing at $1710.33 \mathrm{~cm}^{-1}$ is assigned to the symmetrical stretching vibration of $(\mathrm{C} 2-\mathrm{C} 3)$ in styrene. When $\mathrm{AlCl}_{3}$ in $[\mathrm{BMIM}][\mathrm{Br}]$ is added to styrene and ortho-xylene, the symmetrical stretching vibration of (C2-C3) in styrene is red shifted from $1710.33 \mathrm{~cm}^{-1}$ to $1106.60 \mathrm{~cm}^{-1}$, which illustrates that the $\mathrm{Al}^{3+}$ ion combines with the $\mathrm{C} 3$ atom and decreases the $\mathrm{C} 2-\mathrm{C} 3$ bond strength. The infrared peaks 3165.10 and $3247.26 \mathrm{~cm}^{-1}$ are attributed to $\nu_{\mathrm{s}}(\mathrm{H} 5-\mathrm{C} 3-\mathrm{H} 6)$ and $\nu_{\mathrm{as}}(\mathrm{H} 4-\mathrm{C} 3-\mathrm{H} 5)$, respectively, which are also red shifted to 3026.38 and $3067.59 \mathrm{~cm}^{-1}$, the corresponding vibrational modes are $\nu_{\mathrm{s}}(\mathrm{H} 4-\mathrm{C} 3 \mathrm{Al}-\mathrm{H} 5)$ and $\nu_{\text {as }}(\mathrm{H} 4-\mathrm{C} 3 \mathrm{Al}-\mathrm{H} 5)$, respectively. This indicates that the $\mathrm{Al}^{3+}$ ion joins to form a C3$\mathrm{Al}^{3+}$ bond, which weakens the $\mathrm{C} 3-\mathrm{H} 4$ and $\mathrm{C} 4-\mathrm{H} 5$ bonds. In the product (PXE) the infrared vibrational frequencies 3045.83 and $3119.25 \mathrm{~cm}^{-1}$ correspond to the vibrational modes $\nu_{\mathrm{s}}(\mathrm{H} 5-$ $\mathrm{C} 3 \mathrm{H} 7-\mathrm{H} 6)$ and $\nu_{\text {as }}(\mathrm{H} 5-\mathrm{C} 3 \mathrm{H} 7-\mathrm{H} 6)$, respectively, and the blue shifts of these vibrational frequencies illustrate that $\mathrm{Al}^{3+}$ has been substituted for $\mathrm{H} 7$. The infrared peak at $991.48 \mathrm{~cm}^{-1}$ is the symmetrical stretching vibration of (C2-C3), which may be due to further weakening caused by product formation. The appearance of the vibrational frequency at $3053.79 \mathrm{~cm}^{-1}$, assigned to the symmetrical stretching vibration of (C2-C7), demonstrates a new bond formation between styrene and orthoxylene.

\subsection{Repeated use of the catalyst}

When the amount of ortho-xylene and styrene is 0.03 and $0.005 \mathrm{~mol}$, respectively, and the mole fraction of $\mathrm{AlCl}_{3} /[\mathrm{Bmim}]$ $[\mathrm{Br}]$ is $0.40 \%$, the reactions are carried out at $70{ }^{\circ} \mathrm{C}$ with a reaction time of 1.5 hours. After the reaction, the supernatant liquid is poured out. In order to remove ortho-xylene and volatile organic compounds from the ionic liquid, the reaction vessel was put under vacuum, and then the weight of the raw materials was added. The results are listed in Table 8 . It can be seen that the ionic liquid can still catalyze the reaction and the percentage yield of PXE is larger than 91\% after 6 runs. The activity of the catalyst decreased gradually after 6 runs.

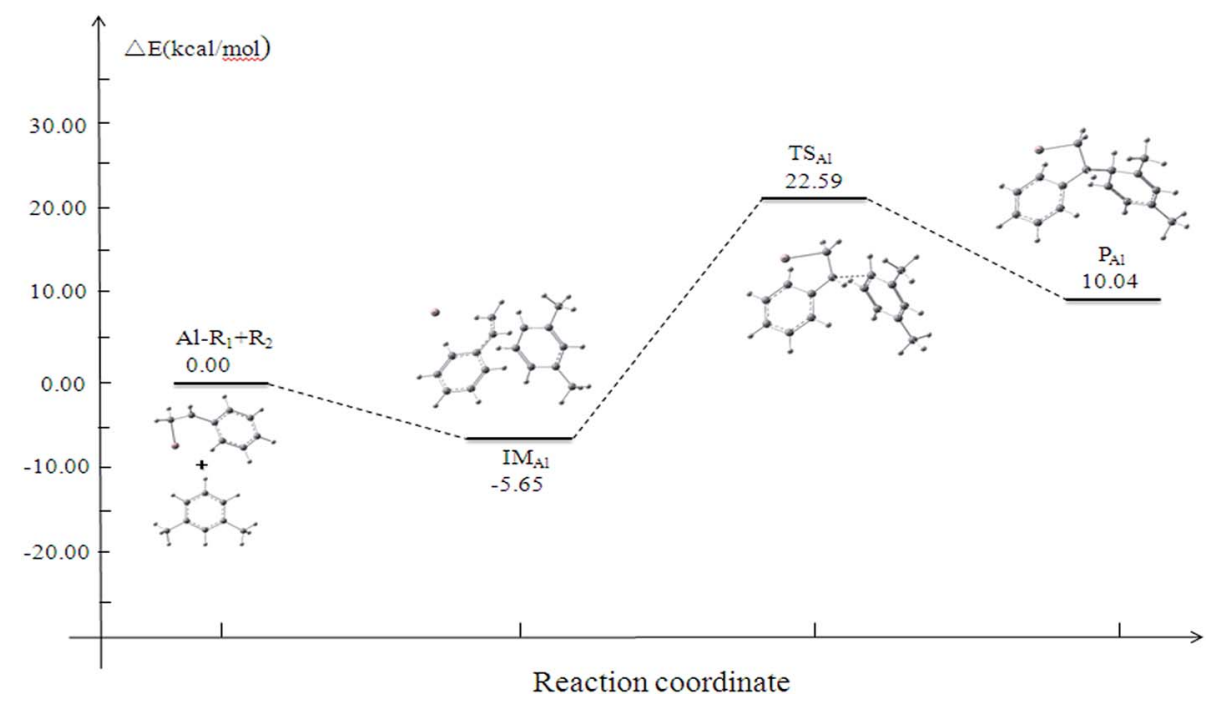

Fig. 2 Energy profiles of the R, IM, TS and P. 
Table 7 Main vibration spectrum variations of styrene, ortho-xylene, styrene + ortho-xylene $+\mathrm{AlCl}_{3}+[\mathrm{BMIM}][\mathrm{Br}]$ and $\mathrm{PXE}$

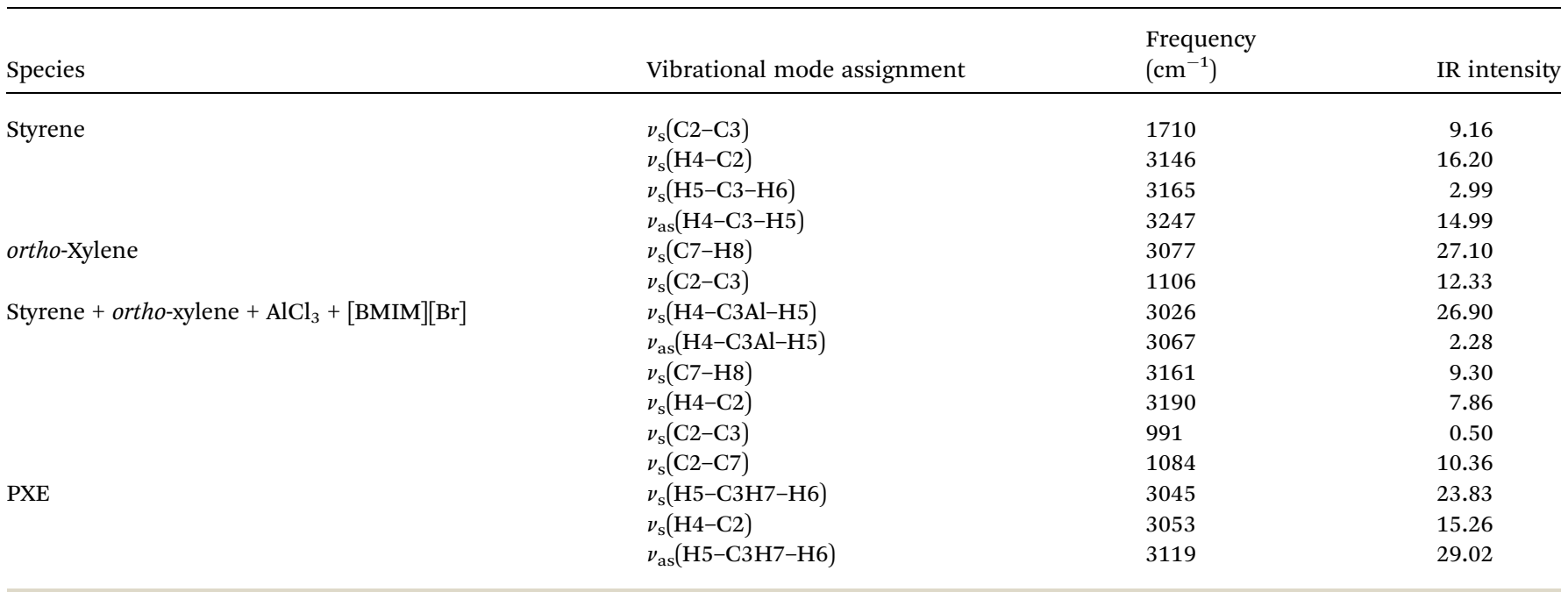

Table 8 Catalyst performance in ionic liquid for repeated operations

\begin{tabular}{lllll}
\hline & & \multicolumn{2}{l}{ Selectivity $(\%)$} & \\
\cline { 3 - 4 } Run & $\begin{array}{l}\text { Percentage conversion } \\
(\%)\end{array}$ & PXE & BPXE & $\begin{array}{l}\text { Yield } \\
(\%)\end{array}$ \\
\hline 1 & 98.5 & 69.7 & 28.3 & 92.8 \\
2 & 98.4 & 69.2 & 28.3 & 93.2 \\
3 & 98.2 & 69.1 & 28.0 & 92.4 \\
4 & 97.8 & 68.5 & 27.5 & 91.8 \\
5 & 97.5 & 68.3 & 27.4 & 91.8 \\
6 & 96.6 & 67.9 & 26.8 & 91.1 \\
7 & 72.3 & 47.7 & 20.5 & 62.0
\end{tabular}

According to Table 8, the activity of the catalyst began to decrease after 3-4 cycles. The main explanations for this are leaching of $\mathrm{AlCl}_{3}$ from the binary mixture and catalyst poisoning by the reaction products and cokes. Measures can be taken to improve the catalytic activity, such as vacuum dehydration, solvent rinsing and the addition of $\mathrm{AlCl}_{3}$. Besides this, further study has been carried out by our group aiming to improve the catalytic efficiency.

\section{Conclusions}

In conclusion, green synthesis of 1-phenyl-1-ortho-xylene ethane in IL and the reaction mechanism are studied. The effects of different catalysts on the reaction are considered, when the amount of $\mathrm{AlCl}_{3}$ in IL, ortho-xylene and styrene are $0.35,0.03$ and $0.005 \mathrm{~mol}$, respectively, the reactions are performed at $30{ }^{\circ} \mathrm{C}$, and the order of the yield is $\mathrm{AlCl}_{3} /[\mathrm{Bmim}][\mathrm{Br}](99 \%)>$ $\mathrm{AlCl}_{3} /[\mathrm{Bmim}][\mathrm{Cl}](73 \%)>\mathrm{H}_{2} \mathrm{SO}_{4}(56 \%)$. The effects of different mole fractions of $\mathrm{AlCl}_{3} /[\mathrm{Bmim}][\mathrm{Br}]$ on the reaction are investigated; results show that as long as the mole fraction concentration of $\mathrm{AlCl}_{3} /[\mathrm{Bmim}][\mathrm{Br}]$ is more than $0.40 \%$, the reaction will be able to achieve $100 \%$ conversion. The effects of different temperatures on the reaction are studied; the percentage conversion of ortho-xylene was increased with the increase of temperature. When the temperature is higher than $60^{\circ} \mathrm{C}$, the percentage conversion of ortho-xylene attained is $100 \%$. The effects of different reaction times on the reaction are investigated; when the reaction time is longer than 60 minutes, the percentage conversion of ortho-xylene attained is $100 \%$. The mechanism of the reaction is discussed by quantum chemical calculations and vibrational frequencies are observed in FT-IR spectra. In addition, the repeated use of the catalyst is considered, the ionic liquid can still catalyze the reaction and the percentage yield of PXE is larger than 91\% after 6 runs. The activity of the catalyst decreased gradually after 6 runs. The activity of the catalyst can be improved by vacuum dehydration, solvent rinsing and the addition of anhydrous $\mathrm{AlCl}_{3}$, which is being studied.

\section{Acknowledgements}

This work was supported by the National Natural Science Foundation of China (No. 21206085 and 21203250).

\section{References}

1 G. A. Olah, Friedel-Crafts Chemistry, John Wiley and Sons, New York, 1973.

2 K. Qiao and Y. Deng, Alkylations of benzene in room temperature ionic liquids modified with $\mathrm{HCl}, \mathrm{J}$. Mol. Catal. A: Chem., 2001, 171, 81-84.

3 E. C. Polo, L. C. d. Silva-Filho, G. V. J. d. Silva and M. G. Constantino, Synthesis of 1-indanones through the intramolecular Friedel-Crafts acylation reaction using $\mathrm{NbCl}_{5}$ as Lewis acid, Quim. Nova, 2008, 31, 763-766.

$4 \mathrm{~T}$. Mu and B. Han, Structures and thermodynamic properties of ionic liquids, in Structures and interactions of ionic liquids, ed. S. Zhang, J. Wang, X. Lu and Q. Zhou, Springer, Berlin, 2014, vol. 151, pp. 107-139.

5 H. Sun, B. Cao, Q. Tian, S. Liu, D. Du, Z. Xue and H. Fu, A DFT study on the absorption mechanism of vinyl chloride by ionic liquids, J. Mol. Liq., 2016, 215, 496-502. 
6 B. Cao, S. Liu, D. Du, Z. Xue, H. Fu and H. Sun, Experiment and DFT studies on radioiodine removal and storage mechanism by imidazolium-based ionic liquid, J. Mol. Graphics Modell., 2016, 64, 51-59.

7 G. Li, C. Yan, B. Cao, J. Jiang, W. Zhao, J. Wang and T. Mu, Highly efficient $\mathrm{I}_{2}$ capture by simple and low-cost deep eutectic solvents, Green Chem., 2016, 18, 2522-2527.

8 B. Cao, J. Du, S. Liu, X. Zhu, X. Sun, H. Sun and H. Fu, Carbon dioxide capture by amino-functionalized ionic liquids: DFT based theoretical analysis substantiated by FT-IR investigation, RSC Adv., 2016, 6, 10462-10470.

9 H.-P. Steinrück and P. Wasserscheid, Ionic liquids in catalysis, Catal. Lett., 2015, 145, 380-397.

10 X. Sun, B. Cao, X. Zhou, S. Liu, X. Zhu and H. Fu, Theoretical and experimental studies on proton transfer in acetatebased protic ionic liquids, J. Mol. Liq., 2016, 221, 254-261.

11 X. Zhou, B. Cao, S. Liu, X. Sun, X. Zhu and H. Fu, Thermal reaction of the ionic liquid 1,2-dimethyl-(3-aminoethyl) imidazolium tetrafluoroborate: a kinetic and theoretical study, J. Mol. Model., 2016, 68, 87-94.

12 Q. Tian, S. Liu, X. Sun, H. Sun, Z. Xue and T. Mu, Theoretical studies on the dissolution of chitosan in acetate-based ionic liquids, Carbohydr. Res., 2015, 408, 107-113.

13 Q. Tian, R. Li, H. Sun, Z. Xue and T. Mu, Theoretical and experimental study on the interaction between 1-butyl-3methylimidazolium acetate and $\mathrm{CO}_{2}$, J. Mol. Liq., 2015, 208, 259-268.

14 J. Jiang, W. Zhao, Z. Xue, Q. Li, C. Yan and T. Mu, PEGylated quasi-ionic liquid electrolytes: fundamental physiochemical properties and electrodeposition of aluminium, ACS Sustainable Chem. Eng., 2016, 4(10), 5814-5819.

15 S. Liu, Y. Chen, Y. Shi, H. Sun, Z. Zhou and T. Mu, Investigations on the thermal stability and decomposition mechanism of an amine-functionalized ionic liquid by
TGA, NMR, TG-MS experiments and DFT calculations, $J$. Mol. Liq., 2015, 206, 95-102.

16 B. Cao, J. Du, D. Du, H. Sun, X. Zhu and H. Fu, Cellobiose as a model system to reveal cellulose dissolution mechanism in acetate-based ionic liquids: density functional theorystudy substantiated by NMR spectra, Carbohydr. Polym., 2016, 149, 348-356.

17 Z. Xue, X. Sun, Z. Li and T. $\mathrm{Mu}, \mathrm{CO}_{2}$ as a regulator for controllable preparation of highly dispersed chitosansupportedPd catalysts in ionic liquid, Chem. Commun., 2015, 51, 10811-10814.

18 X. Zhou, B. Cao, S. Liu, X. Sun, X. Zhu and H. Fu, Theoretical and experimental investigation on the capture of $\mathrm{H}_{2} \mathrm{~S}$ in a series of ionic liquids, J. Mol. Graphics Modell., 2016, 68, 87-94.

19 Z. Zhao, Z. Li, G. Wang, W. Qiao and L. Cheng, Friedel-Crafts alkylation of 2-methylnaphthalene in room temperature ionic liquids, Appl. Catal., A, 2004, 262, 69-73.

20 M. Chen, D. Li, Y. Luo, M. He, J. Xie, H. Li and X. Yuan, Synthesis of 5-benzoylacenaphthene in the presence of Lewis acidic ionic liquids, J. Ind. Eng. Chem., 2011, 17, 14-17.

21 S. F. Boys and F. Bernardi, The calculation of small molecular interactions by the differences of separate total energies. Some procedures with reduced errors, Mol. Phys., 2002, 19(1), 553-566.

22 M. J. Frisch, G. W. Trucks, H. B. Schlegel, G. E. Scuseria, M. A. Robb, J. R. Cheeseman, G. Scalmani, V. Barone, B. Mennucci and G. A. Petersson, et al., Gaussian 09, Revision D.01, Gaussian Inc., Wallingford CT, 2009.

23 C. L. Ricardo, X. Mo, J. A. McCubbin and D. G. Hall, Surprising substituent effect provides a superior boronic acid catalyst for mild and metal-free direct Friedel-Crafts alkylations and prenylations of neutral arenes, Chem.-Eur. J., 2015, 21, 4218-4223. 